\title{
Lesson Study \& Project Based Learning sebagai Upaya Membentuk Forum Diskusi dan Perbaikan Kualitas Pembelajaran Guru IPA
}

\author{
Saleh Hidayat*, Erie Agusta, Rusdy A. Siroj, Yetti Hastiana \\ Fakultas Keguruan dan Ilmu Pendidikan, Universitas Muhammadiyah Palembang \\ *salehhidayat29@gmail.com
}

Submisi: 19 Desember 2017; Penerimaan: 22 Januari 2019

Kata kunci: lesson study; guru IPA; project based learning
Keywords: lesson study, project based learning, science teacher
ABSTRAK Dasar pelaksanaan pengabdian ini adalah permasalahan tentang belum adanya forum bagi kelas IPA SMP N 3 Banyuasin 1 untuk berdiskusi dalam rangka memecahkan permasalahan yang dihadapi di kelas. Tujuan kegiatan pengabdian ini adalah (a) meningkatkan pengetahuan guru IPA SMP N 3 Banyuasin 1 mengenai lesson study dengan model Project Based Learning (PjBL) dan (b) untuk mengetahui tingkat kepuasan peserta terhadap pelaksanaan kegiatan pengabdian. Metode pelaksanaan kegiatan pengabdian meliputi (a) sosialisasi mengenai model PjBL, (b) sosialiasasi tentang lesson study, (c) sosialisasi jenis perangkat pembelajaran, dan (d) pendampingan simulasi pelaksanaan lesson study berbasis $\mathrm{PjBL}$ yang terdiri atas plan, do, dan see. Pengumpulan data pengetahuan dilakukan dengan membagikan soal yang diberikan pada saat sebelum dan sesudah kegiatan PkM. Adapun tingkat kepuasan pelaksanaan pengabdian diperoleh dengan lembar angket. Analisis data pengetahuan dan angket menggunakan analisis deskriptif. Hasil pengabdian menunjukkan bahwa (a) ada peningkatan pengetahuan pada guru IPA SMP N 3 Banyuasin 1 tentang lesson study dengan model PjBL, yakni dari 66 menjadi 74,6, dan (b) ada indikasi bahwa peserta merasa sangat puas terhadap pelaksanaan kegiatan pengabdian.

ABSTRACT The implementation basic of this dedication begun by the problem of having not a forum for science teacher at SMPN 3 Banyuasin 1 to discuss in solving the problems faced at class. This dedication activity was aimed 1) to increase science teachers' knowledge at SMPN 3 Banyuasin 1 about lesson study with project based learning model (PjBL) and 2) to know the level of participant's satisfaction toward the implementation of dedication activity. Implementation Methods of dedication activity included: 1) socialization of the PjBL model; 2) socialization of lesson study; 3) socialization of learning devices types; and 4) assistance of implementation simulation of lesson study based PjBL consisting of plan, do, and see. Data collection of knowledge was done by using the questions given before and after the PkM activity, while the satisfaction level of dedication implementation of devotion was taken by using the questionnaire. Data analysis of knowledge and questionnaire using descriptive analysis. The results of the dedication showed that 1) there was the increase of Science Teachers' knowledge of SMPN 3 Banyuasin 1 about lesson study with PjBL model from 66 to 74,6; and 2) there was the indication of the participants being very satisfied of the implementation of dedication activities. 


\section{PENDAHULUAN}

Kompetensi profesionalisme guru menjadi topik permasalahan yang terus berkembang di Indonesia. Permasalahan yang paling banyak ditemui berkaitan dengan kemampuan guru dalam menguasai materi pembelajaran dan menciptakan pembelajaran yang menarik bagi siswa. Permasalahan ini juga dialami oleh guru-guru IPA di SMP N 3 Banyuasin 1. Berdasarkan fakta yang ditemukan diketahui bahwa guru-guru IPA di SMP N 3 Banyuasin 1 terkadang mengalami kendala ketika mengajarkan materi IPA terpadu. Hal itu disebabkan keterbatasan bidang ilmu guru yang bersangkutan, yakni guru IPA di SMP hanya berlatar pendidikan S-1 Pendidikan Biologi, Pendidikan Fisika, dan Pendidikan Kimia. Kondisi ini membuat banyak guru IPA yang bingung ketika harus mengajarkan materi yang tidak sesuai dengan latar belakang pendidikannya. Materi Biologi di mata pelajaran IPA terpadu SMP, misalnya, akan cukup sulit dipahami oleh guru IPA yang berlatar pendidikan S1 Pendidikan Fisika. Kondisi ini juga dirasakan oleh guru IPA yang berlatar pendidikan S-1 Pendidikan Biologi yang harus mengajarkan materi Fisika di mata pelajaran IPA Terpadu SMP.

Dinas Pendidikan Banyuasin 1 telah berupaya untuk mengatasi masalah tersebut, yakni dengan menyelenggarakan pelatihan peningkatan kompetensi, namun kegiatan tersebut belum memberikan solusi yang maksimal, khususnya bagi guru-guru IPA di SMPN 3 Banyuasin 1. Melihat kondisi ini, tim Pengabdian kepada Masyarakat (PkM) Program Pascasarjana UM Palembang menawarkan sebuah solusi pengenalan lesson study dengan penggunaan Project Based Learning bagi guru-guru IPA di SMPN 3 Banyuasin 1.

\section{MASALAH}

Uraian permasalahan dalam kegiatan pengabdian ini dapat dilihat pada Tabel $\mathbb{1}$ berikut

Tabel 1. Permasalahan Kualitas Pembelajaran di SMP N 3 Banyuasin 1

\begin{tabular}{|c|c|c|c|c|}
\hline No. & $\begin{array}{c}\text { Jenis } \\
\text { Permasalahan }\end{array}$ & $\begin{array}{c}\text { Aspek } \\
\text { Permasalahan }\end{array}$ & Mitra & Solusi \\
\hline 1. & $\begin{array}{l}\text { Model } \\
\text { Pembelajaran }\end{array}$ & $\begin{array}{l}\text { Penggunaan } \\
\text { metode yang } \\
\text { monoton }\end{array}$ & $\begin{array}{l}\text { Guru masih menggunakan } \\
\text { metode konvensional } \\
\text { berupa ceramah (teacher } \\
\text { centered) ketika } \\
\text { mengajar. }\end{array}$ & $\begin{array}{l}\text { Memberi bimbingan dan } \\
\text { pelatihan dalam pembuatan } \\
\text { perangkat pembelajaran } \\
\text { yang meliputi silabus, RPP, } \\
\text { LKS, dan instrumen } \\
\text { penilaian yang berbasis } \\
\text { model PjBL. }\end{array}$ \\
\hline 2. & $\begin{array}{l}\text { Forum diskusi } \\
\text { antarguru }\end{array}$ & $\begin{array}{l}\text { Teknis } \\
\text { pelaksanaan } \\
\text { forum diskusi }\end{array}$ & $\begin{array}{l}\text { Guru belum memiliki } \\
\text { wadah atau forum diskusi } \\
\text { untuk memecahkan } \\
\text { masalah pembelajaran } \\
\text { yang dihadapi. }\end{array}$ & $\begin{array}{l}\text { Memberi bimbingan dan } \\
\text { pelatihan tentang penerapan } \\
\text { lesson study. } \\
\text { Menyusun dan } \\
\text { mensosialisasikan pedoman } \\
\text { pelaksanaan lesson study. }\end{array}$ \\
\hline
\end{tabular}

Sumber: Data primer diolah (2018) 
Berdasarkan tabel di atas diperoleh gambaran bahwa masalah utama yang dihadapi mitra ada dua, yakni mengenai model pembelajaran yang masih monoton dan ketiadaan forum diskusi antarguru IPA di SMP N 3 Banyuasin 1.

\section{METODE}

\subsection{Lokasi, Durasi, dan Bentuk Kegiatan}

Lokasi pengabdian berada di SMP N 3 Banyuasin 1. Pengabdian dilaksanakan pada Rabu 13 Desember 2017 dengan durasi kegiatan 6 jam, yakni dari Pukul 07.00 hingga 13.00 WIB. Bentuk kegiatan pengabdian dibagi berdasarkan jenis permasalahan utama yang dihadapi oleh guru-guru IPA di SMP N 3 Banyuasin 1.

\subsection{Metode Model Pembelajaran}

Permasalahan yang berkaitan dengan model pembelajaran ditindaklanjuti melalui dua tahapan sebagai berikut.

a. Menanamkan pemahaman kepada guru tentang karakteristik model PjBL dalam meningkatkan kreativitas siswa di kelas. Model PjBL ini dipilih karena memiliki kelebihan dalam meningkatkan hasil belajar siswa (Yance, 2013; Jagantara, Adnyana, Widiyanti, 2014). Model ini sesuai dengan karakteristik permasalahan yang dihadapi oleh guru-guru di SMP N 3 Banyuasin 1, yakni yang masih menggunakan metode konvensional berupa ceramah (teacher centered) ketika mengajar.

b. Menginternalisasi pemahaman tentang penerapan model $\mathrm{PjBL}$ dalam wujud perangkat pembelajaran.

\subsection{Metode Forum Diskusi Antarguru}

Permasalahan mengenai belum adanya forum diskusi antarguru ditindaklanjuti dengan melaksanakan lesson study. Pendampingan dan pelaksanaan lesson study dilakukan sebanyak dua siklus. Setiap siklus terdiri atas tiga tahapan utama, yaitu (a) tahap perencanaan (plan), (b) tahap pelaksanaan (do), dan (c) tahap refleksi (see) (Saito, Harun, Kuboki, \& Tachibana, 2006). Rincian kontribusi mitra selama kegiatan ini diuraikan sebagai berikut.

\subsubsection{Lesson Study Siklus I}

Pada lesson study siklus I ini, terdiri dari tiga (3) tahap yaitu tahap perencanaan (plan), tahap pelaksanaan (do), dan tahap refleksi (see). Pada tahap perencanaan (plan) mulai dibentuk beberapa kelompok yang setiap kelompok terdiri atas 3-4 orang, baik guru satu bidang ilmu maupun lintas bidang, seletah itu menentukan ketua dan anggota Tim. Selanjutnya, melakukan diskusi dan mengembangkan perangkat pembelajaran IPA (Fisika, Kimia, Biologi) SMP kelas VII, VIII, dan IX dengan mempertimbangkan materi yang karakteristiknya berkaitan dengan real word problem dan akan diajarkan pada semester yang berjalan. Kemudian menyusun perangkat pembelajaran berupa RPP, LKS, dan instrumen penilaian berbasis model PjBL. Selanjutnya menentukan guru model dan guru pengamat, dan yang terakhir adalah menyiapkan format pengamatan, daftar hadir pengamat, pertanyaan wawancara untuk siswa, dan tata tertib pelaksanaan. 
Sementara itu, pada tahap pelaksanaan (do) dimulainya pelaksanaan perangkat pembelajaran yang telah dikembangkan sebelumnya. Satu orang bertindak sebagai guru model, sementara guru lainnya bertindak sebagai guru pengamat yang bersama-sama bertindak sebagai pengamat proses pelaksanaan uji coba perangkat pembelajaran yang telah disusun. Pengamatan dilakukan menggunakan lembar observasi yang sudah disediakan.

Pada tahap ketiga atau refleksi (see), dilakukan diskusi formal yang membahas hasil pengamatan terhadap pelaksanaan pembelajaran oleh guru pengajar. Diskusi ini dipimpin oleh seorang moderator dan dibantu oleh notulis. Refleksi diawali dengan memberikan kesempatan kepada guru model untuk menyampaikan perasaannya sebelum, saat, dan setelah mengajar. Hal ini bertujuan untuk meningkatkan kualitas pembelajaran berikutnya bagi guru model, sekaligus sebagai refleksi diri bagi pengamat. Pada tahap ini, masukan yang diperoleh dijadikan sebagai acuan untuk perbaikan pada pembelajaran siklus II.

\subsubsection{Lesson Study Siklus III}

Lesson study siklus II terdiri dari tuga (3) tahap yaitu tahap perencanaan (plan), tahap pelaksanaan ( $d o$ ), dan tahap refleksi (see). Pada tahap perencanaan (plan) dilakukan perencanaan pembelajaran berdasarkan kelemahan yang ditemui pada hasil refleksi siklus I. Dilanjutkan dengan tahap pelaksanaan (do) yaitu dengan melaksanakan perangkat pembelajaran yang telah direvisi hasil kegiatan perencanaan siklus II. Tahap terakhir adalah refleksi (see) dengan melakukan diskusi untuk merefleksikan kembali pelaksanaan pembelajaran yang telah dilakukan oleh guru model pada siklus II. Hal-hal yang menjadi fokus perhatian adalah mengenai kelebihan dan juga kekurangan guru model selama pelaksanaan uji coba perangkat pembelajaran tersebut.

Berdasarkan metode yang telah diuraikan dapat diuraikan secara ringkas mengenai metode pelaksanaan yang dapat dilihat pada Gambar 1 berikut ini.

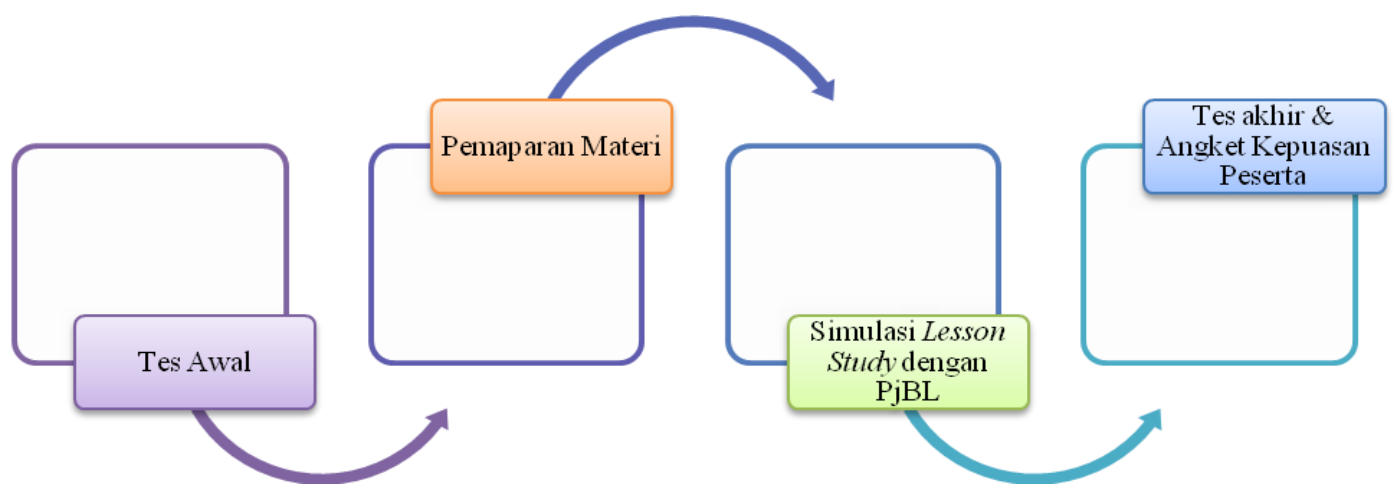

Sumber: Data primer diolah (2018)

Gambar 1. Uraian Singkat Metode Pelaksanaan PkM

\subsection{Teknik Pengumpulan Data}

Pengumpulan data pengetahuan dilakukan melalui soal-soal esai yang terdiri atas lima soal, namun urutan nomor soal tes awal dan tes akhir berbeda karena pengacakan guna meminimalkan terjadinya bias data. Berikut penjabaran pertanyaan soal esai yang disajikan pada Tabel 2. 
Tabel 2. Kisi-Kisi Soal

\begin{tabular}{|c|c|}
\hline Indikator Pengetahuan & Soal \\
\hline $\begin{array}{l}\text { Peserta pengabdian dapat menjelaskan } \\
\text { pengertian lesson study. }\end{array}$ & Apa yang dimaksud dengan lesson study? \\
\hline $\begin{array}{l}\text { Peserta pengabdian dapat menjelaskan } \\
\text { pengertian model } P j B L \text {. }\end{array}$ & $\begin{array}{l}\text { Apa yang dimaksud dengan model Project Based } \\
\text { Learning? }\end{array}$ \\
\hline $\begin{array}{l}\text { Peserta pengabdian dapat menjelaskan } \\
\text { proses pelaksanaan siklus lesson study. }\end{array}$ & Bagaimana cara pelaksanaan lesson study? \\
\hline Peserta pengabdian dapat menjelaskan & Apa saja langkah-langkah model Project Based \\
\hline $\begin{array}{l}\text { langkah-langkah model } P J B L \text {. } \\
\text { Peserta pengabdian dapat menganalisis } \\
\text { kegunaan penerapan lesson study. }\end{array}$ & $\begin{array}{l}\text { Learning? } \\
\text { Mengapa lesson study penting untuk dilakukan di } \\
\text { suatu sekolah? }\end{array}$ \\
\hline
\end{tabular}

Pengumpulan data kepuasan peserta terhadap pelaksanaan pengabdian diambil menggunakan angket. Penjabaran pernyataan angket dapat dilihat pada Tabel 3 berikut ini.

Tabel 3. Kisi-Kisi Angket

\begin{tabular}{|c|c|c|c|}
\hline Dimensi & Aspek & Indikator & No. Pernyataan \\
\hline \multirow{6}{*}{$\begin{array}{l}\text { Kepuasan } \\
\text { Pelaksanaan } \\
\text { Pengabdian }\end{array}$} & Narasumber & Kesesuaian Kompetensi Narasumber & 7 \\
\hline & Waktu & Kesesuain Waktu Pengabdian dengan & 8 \\
\hline & & Kegiatan Guru di Sekolah & \\
\hline & Manfaat & Manfaat Pengabdian bagi Guru IPA & $1,3,4,9,10$ \\
\hline & Kerja sama & Kemampuan Kerja sama Tim PkM & 2,5 \\
\hline & Tim PkM & $\begin{array}{l}\text { Kemampuan Komunikasi Tim PkM } \\
\text { dengan pihak sekolah }\end{array}$ & 6 \\
\hline
\end{tabular}

Sumber: Data primer diolah, 2018

Data pengetahuan dianalisis menggunakan analisis data deskriptif kuantitatif dengan menggunakan rata-rata persentase tes awal dan tes akhir. Data tingkat kepuasan peserta pengabdian terhadap pelaksanaan pengabdian dianalisis secara deskriptif kuantitatif berdasarkan butir pernyataan pada angket.

\section{HASIL DAN PEMBAHASAN}

Kegiatan PkM bagi guru-guru IPA di SMP N 3 Banyuasin 1 dilaksanakan pada Rabu, 13 Desember 2017 dan berjalan lancar. Kegiatan ini diawali dengan sambutan dari Kepala Sekolah SMP N 3 Banyuasin 1 yang kemudian dibuka oleh Direktur PPs UM Palembang. Tahap pertama dilakukan tes awal kepada peserta pengabdian yang dilanjutkan dengan penyampaian materi tentang sosialisasi jenis-jenis perangkat pembelajaran oleh Dr. Yetty Hastiana, M.Si. Narasumber memaparkan bahwa jenis perangkat pembelajaran terdiri atas silabus, RPP, media pembelajaran, bahan ajar, LKS, dan instrumen penilaian. Selain itu, narasumber juga menyampaikan prinsip pengembangan perangkat pembelajaran dan langkahlangkah penyusunannya dalam kurikulum 2013. 
Materi selanjutnya mengenai pengenalan lesson study yang disampaikan oleh Dr. Rusdy A. Siroj, M.Pd. Penyampaian materi diawali dengan pemaparan beberapa permasalahan pendidikan, sejarah lesson study, definisi lesson study, dan tahapan pelaksanaan lesson study yang terdiri atas plan, do, dan see. Selanjutnya, materi model PjBL disampaikan oleh Dr. Saleh Hidayat, M.Si. dan Erie Agusta, M.Pd. Materi diawali dengan pemaparan definisi $P j B L$, manfaat $P j B L$, langkah-langkah $P j B L$, dan beberapa ide proyek yang dapat diterapkan dalam proses pembelajaran. Setelah pemaparan ini berakhir dilanjutkan dengan simulasi lesson study menggunakan model Project Based Learning. Kegiatan simulasi juga dipandu dengan menggunakan buku Panduan Pengabdian kepada Masyarakat: Lesson Study dengan Project Based Learning. Setelah kegiatan simulasi dilaksanakan kemudian dilakukan tes akhir dan pengisian angket kepuasan peserta pengabdian.

\subsection{Pengetahuan dan Kepuasan Guru IPA terhadap Lesson Study dan Project Based Learning (PjBL)}

Hasil pelaksanaan PkM memberikan sumbangsih berupa peningkatan pemahaman guru IPA di SMP N 3 Banyuasin 1 terhadap lesson study dengan penggunaan PjBL. Potensi ini dilihat dari perbandingan antara rata-rata tes awal dengan tes akhir yang tampak pada grafik Gambar 2 berikut ini.

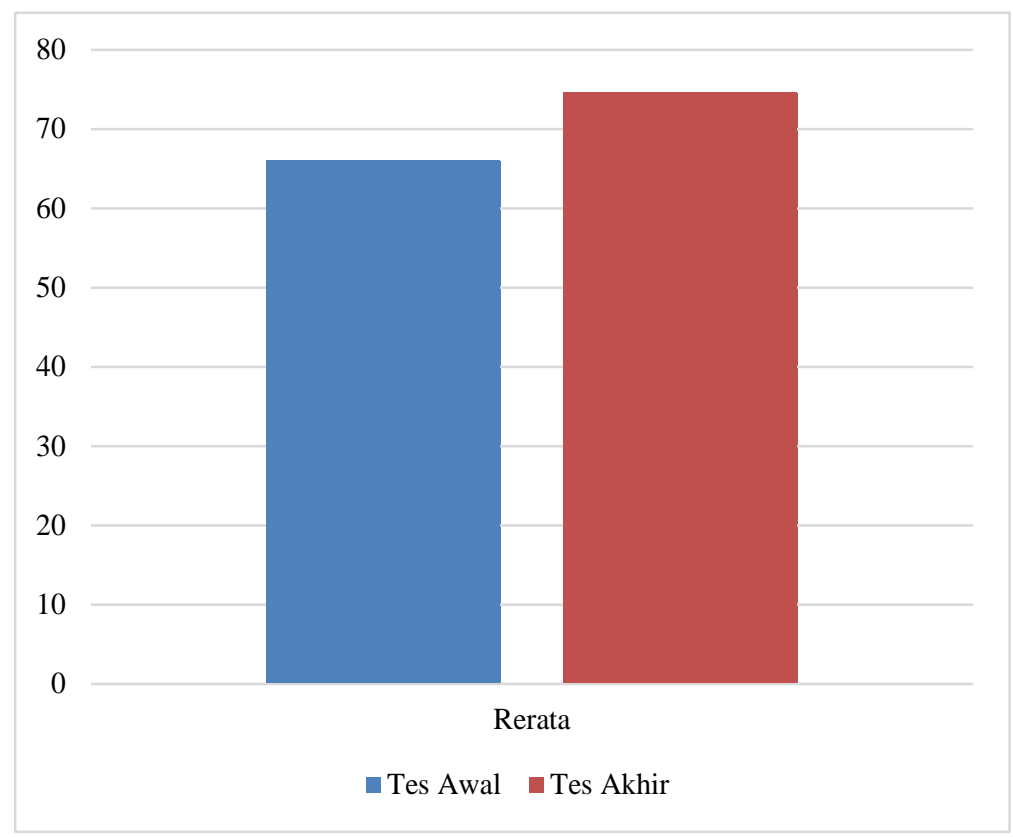

Sumber: Data primer diolah (2018)

Gambar 2 Perbandingan Rerata Tes Awal dan Akhir Guru IPA SMPN 3 Banyuasin 1 saat PkM

Berdasarkan gambar tersebut diperoleh informasi bahwa skor tes awal memiliki nilai rata-rata 66, sedangkan tes akhir 74,6. Hal itu menjadi indikasi keberhasilan kegiatan PkM dalam meningkatkan pengetahuan guru IPA di SMP N 3 Banyuasin 1 mengenai lesson study dengan penggunaaan model Project Based Learning (PjBL). 
Tingkat kepuasan guru IPA di SMP N 3 Banyuasin 1 terhadap pelaksanaan PkM dilihat dari persentase pernyataan pada angket. Berikut disajikan hasil persentase pernyataan angket tersebut.

Tabel 4. Rekapitulasi Persentase Tingkat Kepuasan Guru IPA terhadap Pelaksanaan PkM

\begin{tabular}{clcccc}
\hline No & \multicolumn{1}{c}{ Pernyataan } & SB & B & C & STB \\
\hline 1 & Kesesuaian kegiatan pengabdian dengan kebutuhan Guru IPA & $62 \%$ & $38 \%$ & $0 \%$ & $0 \%$ \\
2 & Kerjasama tim pengabdian dengan masyarakat & $38 \%$ & $62 \%$ & $0 \%$ & $0 \%$ \\
3 & Memunculkan aspek pemberdayaan Guru IPA & $23 \%$ & $77 \%$ & $0 \%$ & $0 \%$ \\
4 & Meningkatkan motivasi Guru IPA untuk berkembang & $54 \%$ & $46 \%$ & $0 \%$ & $0 \%$ \\
5 & Sikap/perilaku tim sosialisasi di lokasi pengabdian & $85 \%$ & $15 \%$ & $0 \%$ & $0 \%$ \\
6 & Komunikasi/koordinasi dengan Kepala SMPN 3 Banyuasin 1 & $62 \%$ & $38 \%$ & $0 \%$ & $0 \%$ \\
7 & Kesesuaian keahlian tim sosialisasi dengan kegiatan & $62 \%$ & $31 \%$ & $7 \%$ & $0 \%$ \\
8 & Kesesuaian waktu pelaksanaan dengan kegiatan Guru IPA & $31 \%$ & $67 \%$ & $2 \%$ & $0 \%$ \\
9 & Kemampuan mendorong kemandirian Guru IPA & $46 \%$ & $54 \%$ & $0 \%$ & $0 \%$ \\
10 & Hasil pengabdian dapat dimanfaatkan Guru IPA & $54 \%$ & $46 \%$ & $0 \%$ & $0 \%$ \\
\hline
\end{tabular}

Keterangan: SB (Sangat Baik), B (Baik), C (Cukup), STB (Sangat Tidak Baik)

Sumber: Data primer diolah (2018)

\subsection{Pembahasan Peningkatan Kualitas Pembelajaran Guru IPA}

Keberhasilan pelaksanaan kegiatan pengabdian tidak lepas dari penggunaan media power point yang disertai video dan keefektifan metode simulasi lesson study berbasis $P j B L$ saat di SMPN 3 Banyuasin 1. Pengunaan media power point disertai video ini melibatkan indra penglihatan dan pendengaran. Penggunaan media dengan melibatkan kedua indra ini akan memberikan pemahaman yang lebih baik (Deal, 2004; Jaenudin, Riswan; Basir, Djahir; Bahtaria, 2012; Maiga \& Bauer, 2013; Saad, Dandashi, Aljaam, \& Saleh, 2015; Taufiq, 2010).

Pemahaman ini juga dikuatkan dengan pelaksanaan simulasi lesson study berbasis PjBL untuk para guru IPA di SMP N 3 Banyuasin 1. Metode simulasi memberikan interaksi fisik dan komunikasi antarguru secara riil sehingga penerapan teori lesson study dengan $P j B L$ lebih mudah dipahami. Argumentasi ini juga didukung oleh beberapa penelitian yang menyatakan bahwa penggunaan metode simulasi dapat meningkatkan pemahaman siswa (Prihatiningtyas, Prastowo, \& Jatmiko, 2013; Putra, 2013; Suhandi, Sinaga, Kaniawati, \& Suhendi, 2009). Keberhasilan kegiatan pengabdian juga tidak lepas dari sikap kooperatif yang diberikan oleh Kepala Sekolah SMP N 3 Banyuasin 1 yang telah menyediakan ruangan untuk pelaksanaan kegiatan dan menyediakan waktu di sela-sela jadwal sekolah agar guruguru IPA dapat mengikuti kegiatan ini

\section{SIMPULAN}

Berdasarkan pelaksanaan kegiatan pengabdian dapat disimpulan hal-hal sebagai berikut. (a) Adanya peningkatan pengetahuan guru-guru IPA di SMP N 3 Banyuasin 1 tentang lesson study dengan model PjBL. Hal itu terlihat dari peningkatan nilai rata-rata tes, yakni 66 pada tes awal menjadi 74,6 pada tes akhir. (b) Adanya indikasi bahwa peserta merasa sangat puas terhadap pelaksanaan kegiatan pengabdian ini. 
Oleh karena itu, kegiatan pelatihan peningkatan kompetensi ini penting dilakukan. Selain untuk meningkatkan pengetahuan guru-guru IPA dilakukan, kegiatan pelatihan ini juga untuk menjaga kinerja dan kualitas guru yang terdapat di SMP N 3 Banyuasin 1.

\section{DAFTAR PUSTAKA}

Deal, W. F. (2004). Using Flash Technology for Motivation and Assessment. The Technology

Teacher, 63(8), 16. Retrieved from

http://search.proquest.com/docview/62119534?accountid=14719\%5Cnhttp://openurl.uq uebec.ca:9003/uqam?url_ver=Z39.882004\&rft_val_fmt=info:ofi/fmt:kev:mtx:journal\&g enre=article\&sid=ProQ:ProQ:ericshell\&atitle=Using+Flash+Technology+for+Motivatio n+and+Assessme

Jaenudin, R., Basir, D., \& Bahtaria, Z. (2012). Pengembangan Bahan Ajar Ekonomi Menggunakan Program Macromedia Flash di Sekolah Menengah Pertama. Jurnal Inovasi Pendidikan, 2(1), 93-106. Retrieved from http://eprints.unsri.ac.id/3888/2/isi-11.pdf

Jagantara, I. M. W., Adnyana, P. B., \& Widiyanti, N. L. P. M., (2014). Pengaruh Model Pembelajaran Berbasis Proyek (Project Based Learning) terhadap Hasil Belajar Biologi Ditinjau dari Gaya Belajar Siswa SMA. Jurnal Pendidikan dan Pembelajaran IPA Indonesia, 4(1).

Maiga, H. A. \& Bauer, M. L. (2013). Using Interactive Flash Games to Enhance Students' Learning in Animal Sciences. NACTA Journal, 57(3), 60-66.

Prihatiningtyas, S., Prastowo, T., \& Jatmiko, B. (2013). Imlementasi Simulasi PhET dan Kit Sederhana untuk Mengajarkan Keterampilan Psikomotor Siswa pada Pokok Bahasan Alat Optik. Jurnal Pendidikan IPA Indonesia, 2(1).

Putra, A. (2013). Perbedaan Hasil Belajar Siswa Melalui Penggunaan Metode Simulasi dengan Metode Ceramah pada Mata Pelajaran Menangani Surat/Dokumen Kantor Kelas XI AP SMK N 2 Padang. Jurnal Pendidikan Ekonomi, 2(3).

Saad, S., Dandashi, A., Aljaam, J. M., \& Saleh, M. (2015). The Multimedia-Based Learning System Improved Cognitive Skills and Motivation of Disabled Children With A Very High Rate. Educational Technology and Society, 18(2), 366-379. Retrieved from https://eric.ed.gov/?id=EJ1070058

Saito, E., Harun, I., Kuboki, I., \& Tachibana, H. (2006). Indonesian lesson study in practice: Case study of indonesian mathematics and science teacher education project. Journal of In-Service Education, 32(2), 171-184. Retrieved from https://doi.org/10.1080/13674580600650872

Suhandi, A., Sinaga, P., Kaniawati, I., \& Suhendi, E. (2009). Efektivitas Penggunaan Media Simulasi Virtual pada Pendekatan Pembelajaran Konseptual Interaktif dalam Meningkatkan Pemahaman Konsep dan Meminimalkan Miskonsepsi. Jurnal Pengajaran MIPA, 13(1), 3548.

Taufiq, O. M. (2010). Pengembangan Bahan Ajar Berbasis Multimedia Melalui Macromedia Flash MX dalam Meningkatkan Kualitas dan Keefektifan Pembelajaran Konsep Dasar Sains II, 2, 1-7. Retrieved from http://jurnal.umuslim.ac.id/index.php/VRS/article/view/132

Yance, R. D. (2013). Pengaruh Penerapan Model Project Based Learning (PBL) terhadap Hasil Belajar Fisika Siswa kelas XI IPA SMA Negeri 1 Batipuh Kabupaten Tanah Datar. Pillar of Physics Education, 1(1). 